\title{
A Numerical Study on the Estimation of Heat Release Rate Based on the Flow Field through the Doorway
}

\author{
SUNG CHAN KIM \\ School of Fire and Disaster Prevention \\ Kyung II University \\ 33, Buho-ri, Hayang-eup, Gyungsan-si, Gyungbook, 712-701, Republic of Korea
}

\begin{abstract}
The present study has been conducted to examine the possibility of estimation of heat release rate using doorway flow in the real structure fire. As a preliminary study to quantify the heat release rate based on the flow field through the opening, a series of CFD calculations for the ISO-9705 room has been performed and compared with experiments. Prior to the full numerical simulation, the grid independence test was performed to optimize the mesh size, and then the doorway flow calculated by the CFD analysis is compared with PIV and bi-directional probe measurements. The chemical and convective heat release rate was obtained by integration of individual cell values through the doorway and the chemical heat release rate by the CFD model was matched well with the nominal heat release rate within $8 \%$. The convective heat release rate through the doorway shows reasonable agreement with the nominal heat release rate having maximum discrepancy of $20 \%$ when considering the heat loss effect. In this matter, this work improves our understanding of heat release rate measurement by doorway flow.
\end{abstract}

KEYWORDS: heat release rate, CFD, compartment fires.

\section{NOMENCLATURE LISTING}

\begin{tabular}{|c|c|c|c|}
\hline$A$ & area $\left(\mathrm{m}^{2}\right)$ & Greek & \\
\hline$c_{p}$ & specific heat $(\mathrm{kJ} / \mathrm{kg} \cdot \mathrm{K})$ & $\alpha$ & thermal diffusivity $\left(\mathrm{m}^{2} / \mathrm{s}\right)$ \\
\hline$h$ & heat transfer coefficient $\left(\mathrm{W} / \mathrm{m}^{2} \cdot \mathrm{K}\right)$ & $\delta$ & thickness (m) \\
\hline$\Delta H_{c}$ & heat of combustion $(\mathrm{kJ} / \mathrm{kg})$ & $\rho$ & density $\left(\mathrm{kg} / \mathrm{m}^{3}\right)$ \\
\hline$k$ & thermal conductivity $(\mathrm{W} / \mathrm{m} \cdot \mathrm{K})$ & subscri] & \\
\hline$\dot{m}$ & mass flow rate $(\mathrm{kJ} / \mathrm{kg})$ & $a$ & ambient \\
\hline$\dot{q}^{\prime \prime}$ & heat flux $\left(\mathrm{W} / \mathrm{m}^{2}\right)$ & $g$ & gas \\
\hline$\dot{Q}$ & heat release rate $(\mathrm{kW})$ & $w$ & wall \\
\hline$t$ & time (s) & $L$ & lower layer \\
\hline$T$ & temperature $(\mathrm{K})$ & $U$ & upper layer \\
\hline$Y$ & mass fraction $(\mathrm{g} / \mathrm{g})$ & $s$ & solid \\
\hline
\end{tabular}

\section{INTRODUCTION}

Heat release rate in the field of fire protection engineering is regarded as a primary parameter to understand the fire phenomena and assess the fire hazards and design of fire protection system. Many important parameters such as fuel burning rate, yield of toxic gases, smoke production, and so on are directly related with the heat release rate from fire, hence, the heat release rate is generally recognized as a measure of hazardness in most fire scenario. Because the thermal energy released from a fire depends on the amount and type of burning material and burning condition, the heat release rate of various burning material has a wide range of its magnitude and transient characteristics in real fire. Therefore, the measurement of heat release rate has been considered as one of the most challenging issue among the fire quantities.

Among the several methods of quantifying the heat release rate, the simplest way is to measure the mass loss rate and consider the heat of combustion of the burning material. However, it has difficulty to quantify for the case of incomplete combustion of fuel vapor from the combustible material and the case having the multi-layered composite material. More advanced approach to quantifying the heat release rate is to measure the thermal energy released from fire or the change of chemical composition during the combustion process. The oxygen consumption principle is based on the assumption that the amount of heat 
released per unit mass of consumed oxygen is approximately constant for most common burning materials and has been widely applied to heat release rate measurement, especially in real scale fire test $[1,2]$.

The key parameter need to determine the heat release rate by the oxygen consumption method is to measure the oxygen deficit during the combustion process [3]. This means that the combustion gases from fire and entrained air should be collected through the hood and exhaust duct system and measured the exhaust mass flow rate and the oxygen and gas concentrations at a sampling location. Therefore, the scale of the fire test is restricted by the hood size and exhaust flow rate of oxygen consumption calorimeter. However, we occasionally need to perform the fire test in a real building environment, not only at real-scale [4] and, it is not easy to estimate the heat release rate in a real structural fire. In this case, the measurement of heat release rate using the traditional oxygen consumption calorimeter is almost impossible due to the limits of size of hood and the fire test facility.

The present study aims to examine the possibility of the heat release rate measurement in real building environment based on the fire driven flow and entrained air flow through the opening of the fire compartment. As the first part of the whole project, the present study has been performed a preliminary approach to apply the traditional measurement technique for quantifying the heat release rate for the simple geometric compartment. A series of CFD (computational fluid dynamics) calculation has been applied to evaluate the heat release rate through the opening of the fire compartment and the process of the present study is divided into following three steps.

- Analysis of grid sensitivity on the fire driven flow in the compartment

- Validation of the CFD model with Rodney's experiments for the doorway flow.

- Evaluation of the chemical and convective heat release rate using doorway flow

It is expected that this study contributes to enhance the understanding of heat release rate measurement and become helpful in accomplishing the advanced measurement technique for the real fire test.

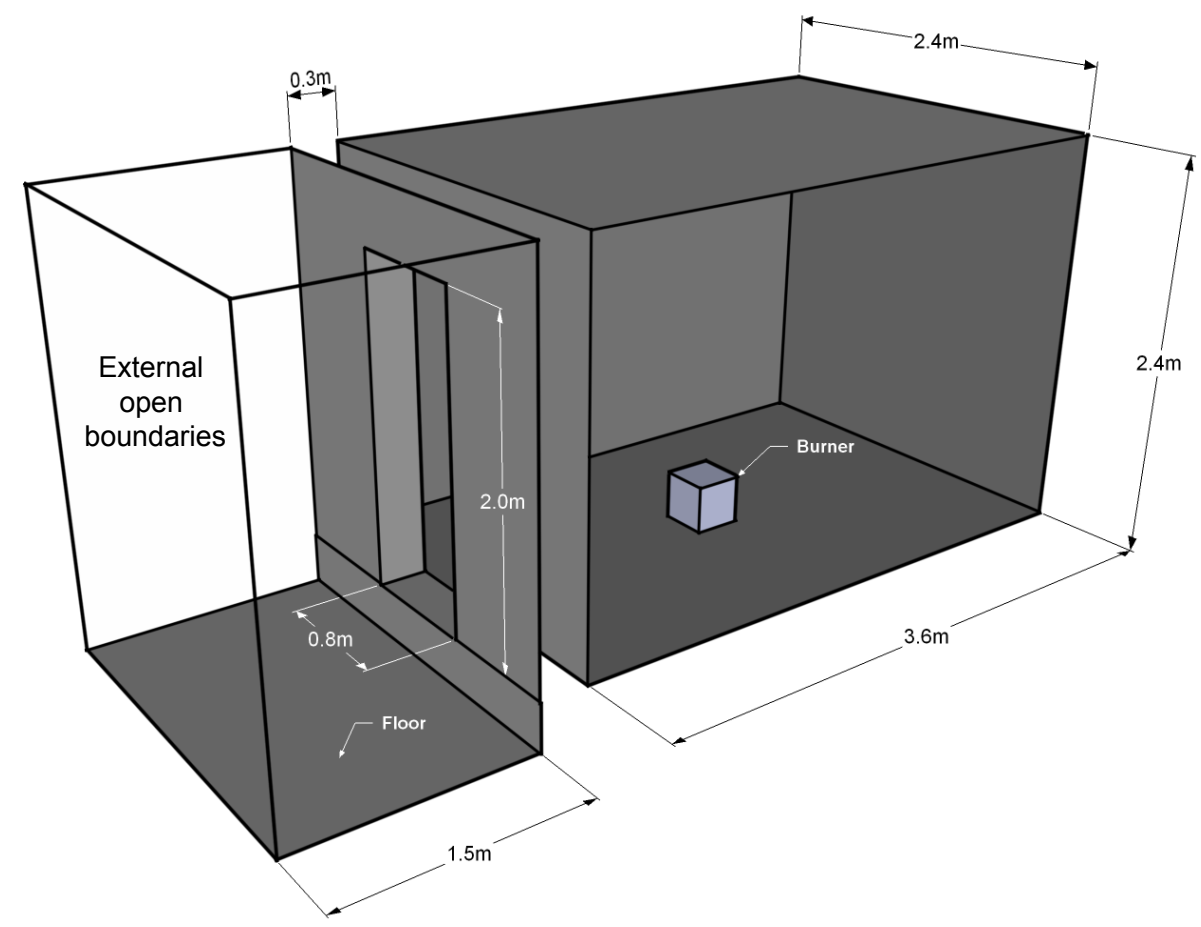

Fig. 1. Schematic of the computational domain of the ISO-9705 compartment.

\section{NUMERICAL SIMULATION}

As a preliminary study to quantify the heat release rate based on the flow field through the opening, the present study performs a series of CFD calculation for the ISO-9705 room fire and examines the 
applicability of the heat release estimation method through the doorway flow. Prior to the full numerical simulation, the grid independence test is performed to ensure the validity of the mesh size in the study. Then, the doorway flow calculated by the CFD analysis is compared with the previous research that had been recently conducted by Rodney Bryant in NIST. Base on the validity of the numerical results, the heat release rate calculated by doorway flow is directly compared with the nominal heat release rate which is given from the fuel mass flow rate.

The experiments were conducted in an ISO 9705 room measuring $2.4 \mathrm{~m} \times 3.6 \mathrm{~m}$ in plane and $2.4 \mathrm{~m}$ in height. The doorway opening measuring $0.8 \mathrm{~m}$ wide by $2.0 \mathrm{~m}$ high was centrally located on the one of the $2.4 \mathrm{~m} \times 2.4 \mathrm{~m}$ walls and its depth was $0.3 \mathrm{~m}$. The natural gas fire was located on the floor in the center of the room and a $30.5 \mathrm{~cm}$ square burner with height of $30 \mathrm{~cm}$ was used for the fire tests. The details of the fire experiments were given by Bryant [5,6]. Figure 1 shows the computational domain corresponds to the fire compartment and extended computational region for outside of the doorway.

The CFD calculations were carried out using CFX version 12.1 [7] which is a commercial computational fluid dynamics (CFD) code. High Reynolds number k- $\varepsilon$ model with buoyancy modification and P-1 radiation model with isotropic spectral model were applied to simulate the turbulent flow and radiative heat transfer in enclosure fire, respectively. The absorption coefficient for the gas was calculated as the mass weighted average of the participating gas species. The fire is modeled by the combustion of $\mathrm{CH}_{4}$ in the eddy dissipation model and a 2-step irreversible reaction mechanism [8] for $\mathrm{CH}_{4}$ combustion was used.

$\mathrm{CH}_{4}+(3 / 2) \mathrm{O}_{2} \rightarrow \mathrm{CO}+2 \mathrm{H}_{2} \mathrm{O}$

$\mathrm{CO}+(1 / 2) \mathrm{O}_{2} \rightarrow \mathrm{CO}_{2}$

The heat flux at the wall boundary in CFD model is calculated using the convective heat transfer coefficient.

$\dot{q}_{w}^{\prime \prime}=h_{c}\left(T_{w}-T_{n}\right)$

where $h_{c}$ is a heat transfer coefficient, $T_{w}$ is the external wall boundary temperature, and $T_{n}$ is the temperature in the neighboring cell on the internal wall boundary. Ceiling and side walls are assumed to have uniform thickness of $2.5 \mathrm{~cm}$ and the external wall heat transfer coefficient and ambient temperature was considered as $10 \mathrm{~W} / \mathrm{m}^{2} \cdot \mathrm{K}$ and $298 \mathrm{~K}$, respectively. Open boundaries on the extended region are set to be $0.0 \mathrm{~Pa}$ of pressure boundary condition.

\section{Grid Independence Test}

Prior to the full CFD simulation, the grid independence test was performed to ensure the feasibility of the mesh size in the study. The grid independence tests were conducted for different mesh and fire size to examine the effect of grid size on the prediction results of fire driven flow in the compartment door. The fire sizes for the grid sensitivity analysis were $34 \mathrm{~kW}$ and $511 \mathrm{~kW}$. The computational domain including inside and outside of the fire compartment is divided by hexahedral type meshes using the ICEM-CFD which is a commercial CAD and grid generation program. The grid tests were carried out for the cells of $52,000,70,000,96,000,136,000$ and 200,000. Figure 2 displays the comparison of the velocity magnitude profiles at the centerline of the doorway. The vertical profiles of velocity magnitude, except near the neutral height of the doorway, were in good agreement for the overall tested mesh size. For the $34 \mathrm{~kW}$ fire, the enlarged figure of Fig. 2a shows a similar trend at the neutral height of the doorway for the cases of grid cells more than 96,000, while the flow direction is opposite for the coarse grid less than 70,000. This means that the predictions with coarse grid show lower neutral height at the center line of the doorway for $34 \mathrm{~kW}$ fire. For the $511 \mathrm{~kW}$ fire, the calculated velocity profile was quite different from the mesh size near the neutral height. However, the calculated velocity profile was well matched for the case of the number of grid cell more than 136,000. Based on the grid independence tests, the present study determined the optimum grid resolution of 136,000 grid cells for ensuring the grid independency and the efficient computation. 


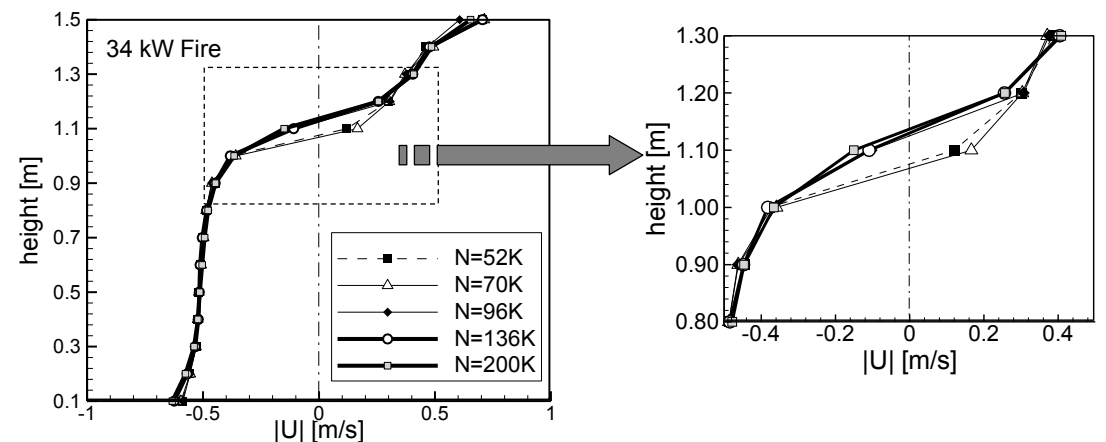

(a)

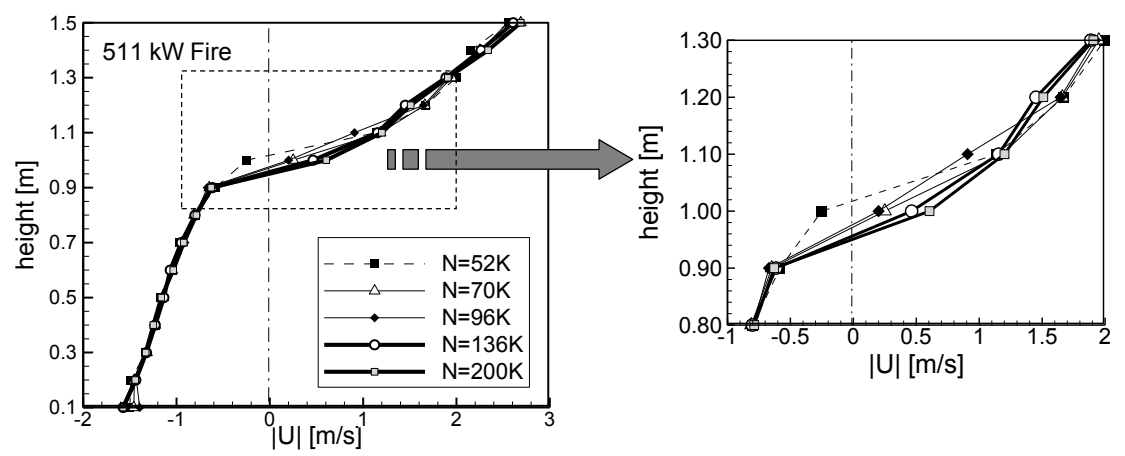

(b)

Fig. 2. Comparison of the vertical velocity profile at the centerline of the doorway with different mesh size for the; (a) $34 \mathrm{~kW}$ fire; (b) $511 \mathrm{~kW}$ fire.

\section{RESULTS AND DISCUSSION}

\section{Numerical Validation}

In order to validate the CFD results for the doorway flow in the fire compartment, the present study compares the velocity profile between CFD calculation and Rodney's experiments for the doorway flow of ISO-9705 room. Figure 3 shows that the vertical profiles of the velocity predicted by CFD model are compared with those of the velocity measurement from the bi-directional probes and PIV at the centerline of the doorway. The predicted velocity profiles of the CFD model are well matched with the experiments for the overall height and give heat release rate. As seen in Fig. 3, the results calculated using the CFD model are in better agreement with the PIV measurements than those measured using bi-directional probes.

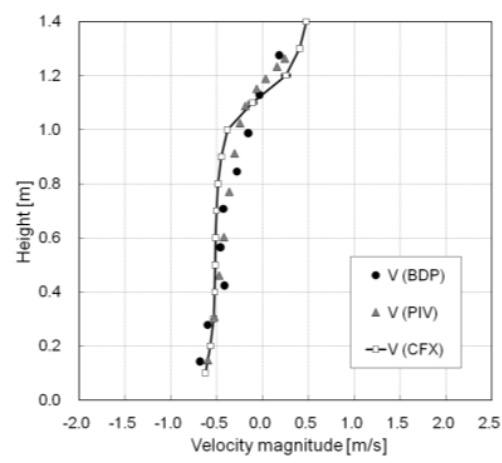

(a)

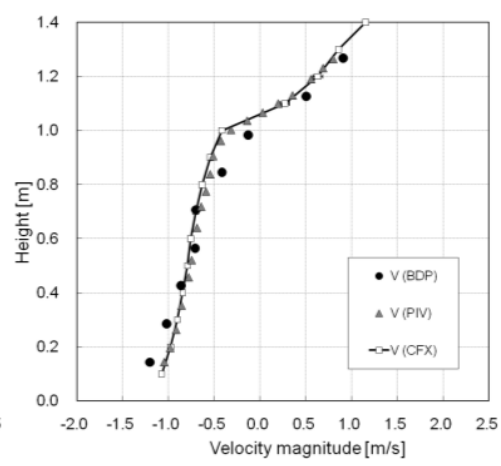

(b)

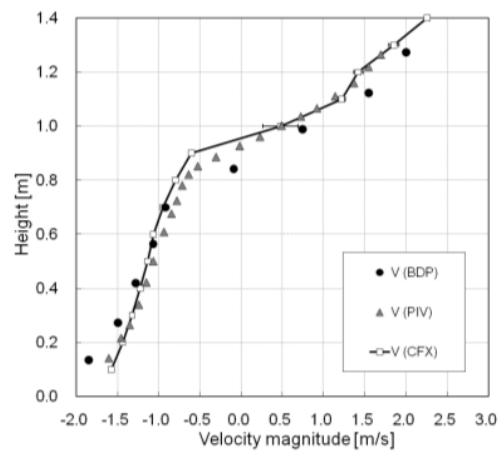

(c)

Fig. 3. Comparisons of vertical velocity profile at the center line of the doorway for the heat release rate of: (a) $34 \mathrm{~kW}$; (b) $160 \mathrm{~kW}$; (c) $511 \mathrm{~kW}$. 
Figure 4 represents the temperature comparison between the CFD calculation and temperature measurement using an aspirated thermocouple for the quasi-steady state fire which is defined by a relatively constant temperature reading in the upper layer inside the compartment during the fire test. The discrepancy between the CFD predictions and experiments was less than $20^{\circ} \mathrm{C}$ for the lower heat release rate than $160 \mathrm{~kW}$, while the CFD model under-predict more than $100{ }^{\circ} \mathrm{C}$ for the $511 \mathrm{~kW}$ fire. Considering the overall performance, the CFD model shows acceptable results for the velocity profile and upper layer temperature in spite of simplicity and limitations of the CFD model used in this study.

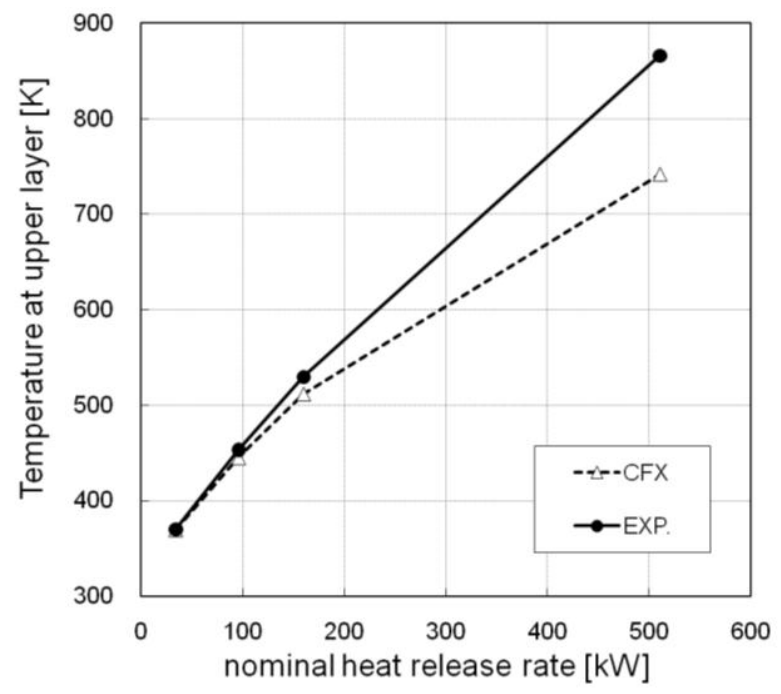

Fig. 4. Comparison between the predicted and measured temperature at a point in the compartment for a quasi-steady state fire condition.

\section{Heat Release Rate Calculation by Doorway Flow}

Based on the validation of the CFD model, the present study examines the heat release rate using the integrating method of oxygen depletion and convective heat release rate through the opening. The chemical heat release rate is defined by the rate of generation of chemical heat from fire and usually determined from the oxygen consumption method [3].

$\dot{Q}_{\text {chem }}=\Delta H_{c, O 2} \cdot\left(\dot{m}_{O 2}^{o}-\dot{m}_{O 2}\right)$

The chemical heat release rate is directly calculated by the oxygen depletion mass flow rate in the system and average heat release per unit mass of oxygen. The main parameters to determine the heat release rate in Eq. 2 are the oxygen mass flow rate of incoming air flow into the system and combustion product from the system. In the compartment fire, the neutral height at the doorway opening is considered as a reference height between the upper part of hot smoke flow from the compartment and the lower part of air flow into the compartment. The individual oxygen mass flow rate can be obtained by the oxygen mass fraction and mass flow rate in the individual cells and the mass flow rate of incoming and outgoing flow can be calculated by the each layer at the doorway. The sign of the incoming flow into the compartment is assumed to be negative.

$\dot{m}_{O 2}^{o}=-\int_{A_{L}} \dot{m} Y_{O 2} d A_{L}$

$\dot{m}_{O 2}=\int_{A_{U}} \dot{m} Y_{O 2} d A_{U}$ 
$\dot{Q}_{\text {chem }}=\Delta H_{c, O 2} \cdot-\int_{A}\left(\dot{m} Y_{O 2}\right) d A=-\int_{A}\left(\Delta H_{c, O 2} \dot{m} Y_{O 2}\right) \cdot d A$

For better understanding of chemical heat through the doorway, this study introduces $\dot{q}_{\text {chem }, i}$ for the individual cell at the doorway as follows;

$\dot{q}_{c h e m, i}=\Delta H_{c, O 2} \cdot \dot{m}_{i} \cdot Y_{O 2, i}$

Figure 5 shows the calculated field of $\dot{q}_{\text {chem }}$ for the nominal heat release rate of $34 \mathrm{~kW}$ and $160 \mathrm{~kW}$ fire at the cross section of the doorway. Because the sign of $\dot{q}_{\text {chem }}$ is determined by the flow direction through the doorway, $\dot{q}_{\text {chem }}$ is positive in the upper part of the doorway while negative in the entrained air flow into the room. Therefore, the integration of $\dot{q}_{\text {chem }}$ represents the chemical heat release rate calculated by the difference of oxygen mass flow rate between incoming and outgoing flow through the doorway. The calculated chemical heat release rate based on the doorway flow for the nominal heat release rate of $34 \mathrm{~kW}$ and $160 \mathrm{~kW}$ fire are about $33 \mathrm{~kW}$ and $166 \mathrm{~kW}$, respectively. For the $511 \mathrm{~kW}$ fire, the calculated chemical heat release rate is about $548 \mathrm{~kW}$ and the discrepancy between the nominal and the calculated heat release rate do not exceed $8 \%$. This means that the calculation method based on the oxygen consumption method for the doorway flow may be quite effective to evaluate heat release rate.

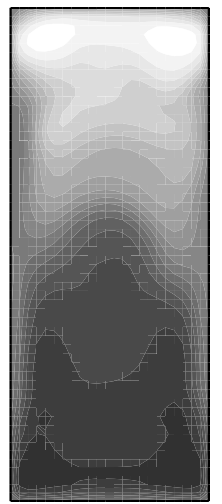

(a)

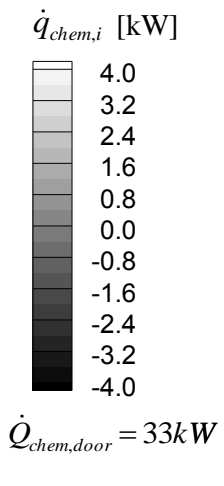

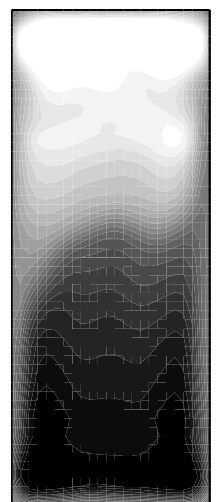

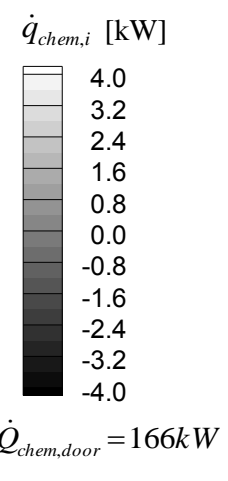

(b)

Fig. 5. Contour plots of the chemical heat release rate at the cross-section of the doorway: (a) $34 \mathrm{~kW}$; (b) $160 \mathrm{~kW}$.

In contrast to the chemical heat release rate, the convective heat release rate in an individual cell is mainly determined from the gas temperature rise and mass flow rate.

$$
\dot{q}_{c o n v, i}=\dot{m}_{i} C_{p, i} \Delta T
$$

where the $\dot{m}$ and $\Delta T$ represent the mass flow rate and the temperature rise of combustion product-air mixture, respectively. The convective heat release rate through the doorway is obtained by the integration of the convective heat release rate in the individual cell through the doorway.

$$
\dot{Q}_{c o n v}=\int_{A} \dot{q}_{c o n v, i} d A=\sum_{i=1}^{N} \dot{m}_{i} C_{p, i}\left(T_{g, i}-T_{a}\right)
$$

The convective heat release rate due to the incoming air flow is negligible due to small temperature difference through the lower layer of the doorway. Figure 6 demonstrates the calculated field of $\dot{q}_{\text {conv }}$ for the nominal heat release rate of $34 \mathrm{~kW}$ and $160 \mathrm{~kW}$ fire at the cross section of the doorway. As expected, 
$\dot{q}_{\text {conv }}$ is close to zero in the lower part of the doorway while relatively high in the upper part of the doorway. The convective heat release rate for the $34 \mathrm{~kW}$ and $160 \mathrm{~kW}$ fire are $22 \mathrm{~kW}$ and $110 \mathrm{~kW}$ and this means that the fraction of convective heat release rate through the doorway are about 0.65 and 0.7 , respectively. For the $511 \mathrm{~kW}$ fire, $\dot{q}_{c o n v}$ was $363 \mathrm{~kW}$ and its fraction is approximately $71 \%$. Therefore, fraction of heat loss in the fire compartment is approximately $30 \%$ of the generated heat from the fire. For the quasi-steady state fire, we can assume that the heat release rate in the compartment is equivalent with the sum of rate of heat loss due to gas flow through opening and the rate of heat loss to the compartment boundaries.

$\dot{Q}=\dot{Q}_{\text {conv }}+\dot{Q}_{\text {loss }}$

In order to examine the heat loss in the fire compartment, a well known simple formula is applied to estimate the heat loss to the compartment boundaries [9]. The heat loss to the boundaries involves many heat transfer modes and the dominant heat transfer process is conductive heat loss to the solid wall. The heat loss term can be written as follows;

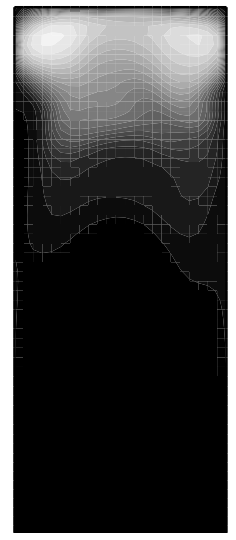

(a)

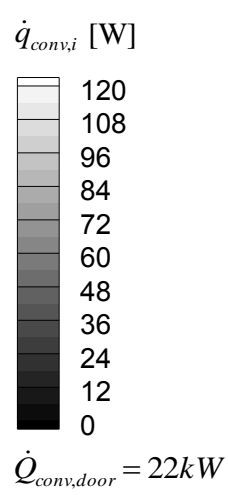

Fig. 6. Contour plots of the convective heat release rate at the cross section of the doorway: (a) $34 \mathrm{~kW}$;

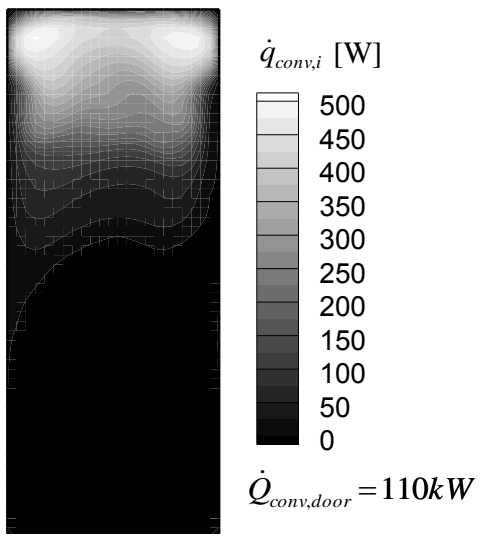

(b) (b) $160 \mathrm{~kW}$.

$\dot{Q}_{\text {loss }}=h_{k} A_{T}\left(T_{g}-T_{a}\right)$

where $h_{k}$ is the effective heat transfer coefficient, $A_{T}$ is the interior surface area in the compartment, $T_{g}$ and $T_{a}$ denote the upper layer and ambient temperature. For the effective heat transfer coefficient, McCaffrey et al. defined $h_{k}$ as follows;

$h_{k}=\left\{\begin{array}{cc}\sqrt{\frac{k \rho C_{s}}{t}} & \left(t<t_{p}\right) \\ \frac{k}{\delta} & \left(t \geq t_{p}\right)\end{array}\right.$

here $C_{s}$ is the specific heat, $\delta$ is the thickness of the sold material, and the thermal penetration time, $t_{p}$, can be given as

$t_{p}=\frac{\delta^{2}}{4 \alpha}$ 
where $\alpha$ is the thermal diffusivity. The material properties of calcium silicate board are listed in Table 1.

Table 1. Typical thermal properties for the calcium silicate board.

\begin{tabular}{|c|c|c|c|}
\hline $\begin{array}{c}\text { Thermal conductivity, } \boldsymbol{k} \\
(\mathbf{W} / \mathbf{m} \cdot \mathbf{K})\end{array}$ & $\begin{array}{c}\text { Specific heat, } \boldsymbol{C}_{\boldsymbol{s}} \\
(\mathbf{J} / \mathbf{k g} \cdot \mathbf{K})\end{array}$ & $\begin{array}{c}\text { Density, } \boldsymbol{\rho} \\
\left(\mathbf{k g} / \mathbf{m}^{\mathbf{3}}\right)\end{array}$ & $\begin{array}{c}\text { Thermal diffusivity, } \boldsymbol{\alpha} \\
\left(\mathbf{m}^{\mathbf{2}} / \mathbf{s}\right)\end{array}$ \\
\hline 0.055 & 840 & 475 & $1.38 \times 10^{-7}$ \\
\hline
\end{tabular}

In Eq. 10, the mean gas temperature in the upper layer is not easily determined in CFD model and experiment. The present study assumes that the measured temperature in Fig. 4 is used as $T_{g}$ to calculate heat loss to the boundary wall. The heat loss calculated by Eq. 10 is compared with integration of heat loss to the wall boundary with CFD macro function and summarized in Table 2.

Table 2. Calculated heat loss in the fire compartment for the nominal heat release rate.

\begin{tabular}{|c|c|c|}
\hline$\dot{Q}$ & $\dot{Q}_{\text {loss }}$ calculated by Eq. 10 & $\dot{Q}_{\text {loss }}$ calculated by the CFD model \\
\hline $34 \mathrm{~kW}$ & $19 \mathrm{~kW}$ & $10 \mathrm{~kW}$ \\
\hline $160 \mathrm{~kW}$ & $57 \mathrm{~kW}$ & $42 \mathrm{~kW}$ \\
\hline $511 \mathrm{~kW}$ & $119 \mathrm{~kW}$ & $124 \mathrm{~kW}$ \\
\hline
\end{tabular}

The heat loss in CFD model is calculated by the local temperature in the upper layer of the fire compartment. As seen in Table 2, the heat loss calculated by the measured temperature at a point of upper layer over-estimate than those of CFD model for the $34 \mathrm{~kW}$ and $160 \mathrm{~kW}$ fire, while under-estimated for the $511 \mathrm{~kW}$ fire. Except the case of $34 \mathrm{~kW}$ fire, the result of Eq. 10 shows an acceptable agreement with CFD model.

Figure 7 summarizes the calculated heat release rate by doorway flow for the given fire size. The convective heat release rate has approximately $30 \%$ discrepancy comparing with nominal heat release rate, while the chemical heat release rate using oxygen consumption through the doorway was less than $8 \%$. However, the overall discrepancy of the convective heat release rate including heat loss term was less than $10 \%$ except the case of $34 \mathrm{~kW}$ fire with heat loss calculated by empirical correlation of Eq. 10.

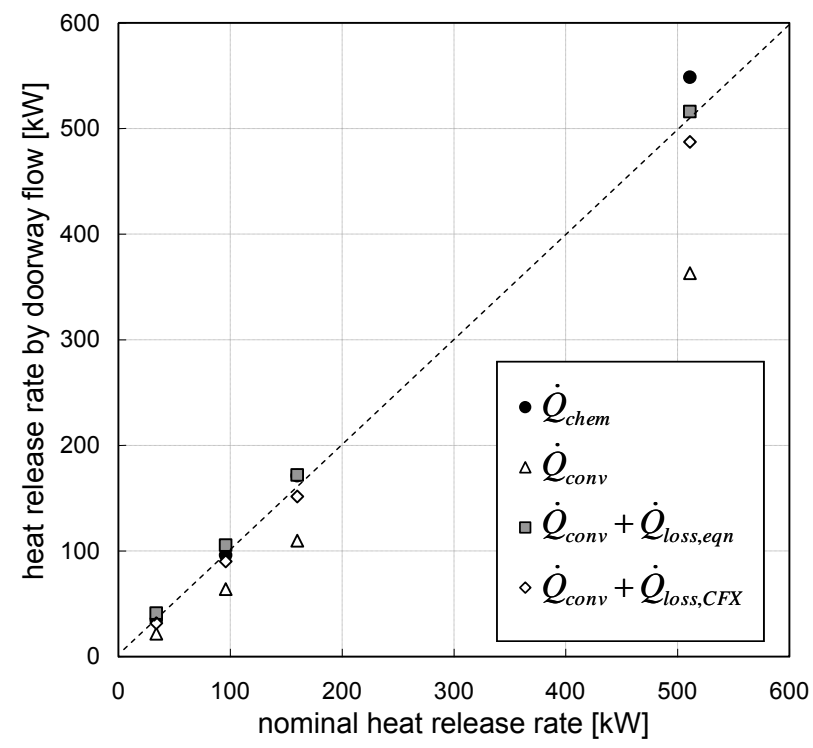

Fig. 7. Comparison of the estimated heat release rate based on the chemical and convective heat release rate with and without heat loss for the given nominal heat release rate. 


\section{SUMMARY AND CONCLUSIONS}

As a preliminary study of the heat release rate estimation in real structural fire, the chemical and convective heat release rate based on the doorway flow of ISO-9705 room was investigated using a CFD model validated with experiments. The CFD model was validated using experimental measurements for the vertical velocity profile at the centerline of the doorway and temperature in the upper layer inside the fire compartment. The velocity profiles for the CFD results were in good agreements with the measured velocity using PIV technique and bi-directional probe. The predicted temperature by the CFD model was well matched with experiments within $20^{\circ} \mathrm{C}$ for the case of the heat release rate less than $160 \mathrm{~kW}$, while under-predicted more than $100^{\circ} \mathrm{C}$ for the $511 \mathrm{~kW}$ fire. But this discrepancy can be considered as acceptable results for performing the main objective of the present study.

In order to evaluate the chemical heat release rate, the oxygen consumption method was rearranged for the doorway flow based on the reference height of the doorway. The chemical heat release rate was obtained by integrating of $\dot{q}_{c h e m}$ at individual cells across the doorway and the predicted $\dot{Q}_{c h e m}$ was well matched with the nominal heat release rate within $8 \%$. The discrepancy of the predicted convective heat release rate by the CFD model was approximately $30 \%$ without considering heat loss to solid boundaries, but it was less than about $20 \%$ with considering the heat loss effect. This means that the measurement of convective heat release rate through the opening may be useful way to estimate the rate of energy released in the structural fire.

In order to apply this approach to real structural fire, we still need to study for various fuel type and fire size but also have many challenging works such as field measurement of velocity and oxygen concentration. Nevertheless, this work shows the possibility of estimation of heat release rate using doorway flow.

\section{ACKNOWLEDGEMENT}

The author is grateful to Dr Rodney Bryant for helpful discussion on the velocity measurement in a enclosure fire and this research was supported by Basic Science Research Program through the National Research Foundation of Korea (NRF) funded by the Ministry of Education, Science and Technology (20100013091)

\section{REFERENCES}

[1] Babrauskas, V., "Heat Release Rates," The SFPE Handbook of Fire Protection Engineering ( $3^{\text {rd }}$ ed.), DiNenno P.J. (ed.), National Fire Protection Association, Quincy, MA 02269, 2002, p. 3-1.

[2] Huggett, C., (1981) Estimation of Rate of Heat Release by Means of Oxygen-Consumption Measurement, Fire and Materials 4: 61-65, http://dx.doi.org/10.1002/fam.810040202

[3] Rodney, R.A., Ohlemiller T.J., Johnsson, E.L., Hamins, A., Grove, B.S., Guthrie, W.F., Maranghides, A., and Mulholland, G.W., "The NIST 3 Megawatt Quantitative Heat Release Rate Facility - Description and Procedures," National Institute of Standards and Technology Report NISTIR 7052, Gaithersburg, MD, 2004, 5 p.

[4] Kim, M.B., Han, Y.S., Choi, B.I., and Do, K.H, (2009) A Full-Scale Fire Test in an Apartment House, Journal of Korean Institute of Fire Science 23: 104-111.

[5] Bryant, R.A., (2009) A comparison of gas velocity measurements in a full-scale enclosure fire, Fire Safety Journal, 44: 793-800, http://dx.doi.org/10.1016/j.firesaf.2009.03.010

[6] Bryant, R.A. (2009) The Application of Stereoscopic Particle Image Velocimetry to Measure the Flow of Air into an Enclosure Containing a Fire, Experiments in Fluids 47: 295-308, http://dx.doi.org/10.1007/s00348-009-0656-Z

[7] ANSYS Inc., (2009) ANSYS CFX-Pre User's Guide 12.1

[8] Westbrook, C.K., and Dryer, F.L., (1981) Simplified Reaction Mechanism for the Oxidation of Hydrocarbon Fuels in Flames, Combustion Science and Technology 27: 31-43, http://dx.doi.org/10.1080/00102208108946970 